\title{
Extraction and Separation Factor for Lanthanum(III) and Cerium(III) Complexes from Aqueous Medium Using Ionic Liquid and Kerosene
}

\author{
Angelica Quintriqueo1 ${ }^{*}$, Julio Romero ${ }^{1}$, Esteban Quijada-Maldonado ${ }^{1}$, E. Bringas ${ }^{2}$, \\ Felipe Olea ${ }^{1}$, Jose Hernández ${ }^{3}$
}

\author{
${ }^{1}$ Laboratory of Membrane Separation Processes (LabProSeM), Department of Chemical Engineering, University of Santiago de \\ Chile, Estación Central, Chile \\ ${ }^{2}$ Department of Chemical and Biomolecular Engineering, ETSIIT, University of Cantabria, Santander, Spain \\ ${ }^{3}$ Advanced Materials Department, Chilean Nuclear Energy Commission, Santiago, Chile \\ Email: *angelica.quintriqueo@usach.cl
}

How to cite this paper: Quintriqueo, A., Romero, J., Quijada-Maldonado, E., Bringas, E., Olea, F. and Hernández, J. (2020) Extraction and Separation Factor for Lanthanum(III) and Cerium(III) Complexes from Aqueous Medium Using Ionic Liquid and Kerosene. Advances in Chemical Engineering and Science, 10, 343-357.

https://doi.org/10.4236/aces.2020.104022

Received: July 9, 2020

Accepted: September 15, 2020

Published: September 18, 2020

Copyright $\odot 2020$ by author(s) and Scientific Research Publishing Inc. This work is licensed under the Creative Commons Attribution International License (CC BY 4.0).

http://creativecommons.org/licenses/by/4.0/ (c) (i) Open Access

\begin{abstract}
In this work, an experimental study was carried out to find the best-operating conditions for the study of the extraction percentage (\%E) and the separation factor (SF) of $\mathrm{La}(\mathrm{III})$ and $\mathrm{Ce}(\mathrm{III})$ complexes. To carry out this study, a variation of $\beta$-diketone concentrations was used, keeping the concentration of tri-octyl phosphine oxide (TOPO) continuous at $0.05 \mathrm{M}$. The ratio of organic phase to the aqueous phase $(\mathrm{O} / \mathrm{A})$ was also studied. The $\% \mathrm{E}$ and SF were analyzed and compared in the 1,1,1-trifluoro-2,4-pentanedione (TFA) with TOPO, and 1,1,1,5,5,5-Hexafluoro-2,4-pentanedione (HFAc) with TOPO in Ionic Liquid (IL) and Kerosene. The one-stage extraction efficiency in IL of $\mathrm{La}(\mathrm{III})$ and $\mathrm{Ce}(\mathrm{III})$ complexes was $42.13 \%$ and $77.48 \%$ for the TFA-TOPO system and $\mathrm{La}(\mathrm{III})$ and $\mathrm{Ce}(\mathrm{III})$ complexes were $94.33 \%$ and $97.67 \%$ for the HFAc-TOPO system. While the SF between Ce(III) and La(III) complexes was 4.91 for TFA-TOPO and 2.64 for HFAc-TOPO. On the other hand, the one-stage extraction efficiency in Kerosene of $\mathrm{La}(\mathrm{III})$ and $\mathrm{Ce}(\mathrm{III})$ complexes was $27.57 \%$ and $63.70 \%$ in the TFA-TOPO system. The one-stage extraction efficiency of $\mathrm{La}(\mathrm{III})$ and $\mathrm{Ce}(\mathrm{III})$ complexes were $99.87 \%$ and $99.73 \%$ for the HFAc-TOPO system in Kerosene while the SF between Ce(III) and $\mathrm{La}(\mathrm{III})$ complexes was 4.62 for TFA-TOPO and 0.49 for HFAc-TOPO. The main conclusion was that using two extractants ( $\beta$-diketone and TOPO) produced a synergistic effect improving the extraction capacity and SF of $\mathrm{La}(\mathrm{III})$ and $\mathrm{Ce}$ (III) complexes for both systems in IL and Kerosene.
\end{abstract}




\section{Keywords}

Synergistic Extraction, $\beta$-Diketone, Tri-Octyl Phosphine Oxide, Lanthanide Complex

\section{Introduction}

Lanthanide elements (Lns: La-Lu; 57 - 71) belong to the rare earth series. They are critical in many high-tech industries, such as hybrid cars, wind turbines, flat-screen televisions, mobile phones, and defense technologies [1]. Their properties change gradually across the Lns series. Their ionic size and the coordination number decrease while the surface charge density increases. Selective separation of a Lanthanide(III) among the Lns series is challenging [2] [3]. Separating two adjacent $\mathrm{Ln}$ (III) such as Cerium(III) (Ce(III)) and Lanthanum(III) ( $\mathrm{La}(\mathrm{III}))$ is a great challenge for this study.

The numerous technologies employed for the separation and purification of the Lns(III), synergistic solvent extraction (SSX), offer a competitive alternative. SSX of Ln(III) ions with two kinds of extractants, is one of the most efficient methods for separation technology because of its speed, simplicity, and improvement of the extraction efficiency and the selectivity [4]. An example has been $\beta$-diketone with other extractants for Lns(III) separations [5].

The $\operatorname{Ln}(\mathrm{III})$ - $\beta$-diketone complexes have been for various applications. In trace analysis of lanthanide ions, organic and biomolecular compounds, visualization luminescence of latent fingerprints, chemical sensors, and volatile complexes, among others [6]. Many different $\beta$-diketones are commercially available, and the synthesis of the corresponding Lns(III) complexes is relatively easy. The $\beta$-diketones exhibit a significant tendency towards cationic selectivity between Lns(III) [7] [8].

The synergistic extractability and the separation factor (SF) can be ascribed to the adduct formation of $\operatorname{Ln}(\mathrm{III})$ - $\beta$-diketones with neutral ligands in the organic phase and lowered with an increase in the atomic number of $\operatorname{Ln}($ III) in the $\beta$-diketone-TOPO [9] [10]. Also, Okamura et al., found that the SF between La and $\mathrm{Ce}, \mathrm{Pr}$ and $\mathrm{Nd}, \mathrm{Sm}$ and $\mathrm{Eu}$, and $\mathrm{Eu}$ and Gd with Htta and TOPO in $\left[\mathrm{C}_{4} \mathrm{mim}\right]\left[\mathrm{Tf}_{2} \mathrm{~N}\right]$ is higher than that with D2EHPA or PC-88A in isooctane [9]. Additionally, the separation of $\operatorname{Ln}$ (III) varied with the acidity of the $\beta$-diketones used as the extractants. The SF between $\mathrm{Eu}(\mathrm{III})$ and $\mathrm{Lu}(\mathrm{III})$ in the synergistic system using benzoylacetone ( $\mathrm{Hba}$ ) with a higher $\mathrm{pKa}$ is significantly larger than those with other $\beta$-diketones [11]. Furthermore, it is usually necessary to use an auxiliary ligand, such as TOPO, to saturate the remaining sites in the lanthanide coordination sphere and exclude water [12] [13]. Therefore, the $\beta$-diketones have been used in various synergistic combinations to achieve high Lns(III).

Ionic liquids (ILs) have been considered as alternative solvents for solvent extraction processes because of their properties such as low volatility, low vapor 
pressure, excellent chemical stability, adjustable miscibility, and polarity, making ILs attractive replacements for current organic solvents.

(VOCs) [14]. Some studies have used ILs as solvent of extraction of $\operatorname{Ln}(\mathrm{III})$. In the researches, highly selective synergism for the removal of lanthanoid(III) Ions with $\beta$-diketones and TOPO in an Ionic Liquid [9] [15]. Synergistic of the extraction and separation efficiencies of lanthanoid(III) Ions by forming charged adducts in an ionic liquid [9]. The cation and anion exchange mechanisms are specific to ILs extraction systems, often leading to improved extraction capacity and separability of $\operatorname{Ln}(\mathrm{III})$ and achieving competitive advantage results in VOCs [16] challenging goal in Lns(III) separation is to develop an effective process to improve separation and minimize environmental contamination. The desired solvent should be non-volatile, non-flammable, low toxicity, high efficiency, high stability, low cost, weak acid, and base. These characteristics are fundamental to the extraction of Lns(III). In recent years, as a green solvent, ionic liquids gained considerable attention. They showed tremendous potential for an eco-friendly Lns(III) separation.

The work aims to perform synergistic extraction using an organic phase containing a solvent medium with a $\beta$-diketone (HFAc or TFA) and TOPO. The solvent medium used was ionic liquid or kerosene, the aqueous phase containing $\mathrm{Ce}$ (III) and $\mathrm{La}(\mathrm{III})$. The challenge of this study is to achieve the best operational conditions to carry out a high SF of $\mathrm{Ce}(\mathrm{III}) / \mathrm{La}(\mathrm{III})$ complexes. The extraction percentage (\%E) and the Separation Factor (SF) of Lns complexes will be obtained and analyzed for $\mathrm{La}(\mathrm{III})$ and $\mathrm{Ce}(\mathrm{III})$ complexes. Additionally, the O/A ratio will be studied and evaluated in the first extraction stage.

\section{Materials and Reagents}

The ionic liquid used in this study was 1-Butyl-3-methylimidazoliumbis-(trifluoromethylsulfonyl)-imide $\left([\mathrm{Bmim}]\left[\mathrm{Tf}_{2} \mathrm{~N}\right]\right)$ which was supplied by IO-LI-TEC ${ }^{\circ}$ (Heilbronn, Germany) with a 99\% purity. Kerosene was provided by Shellsol D70. The chosen extractants were the $\beta$-diketone 1,1,1-trifluoro-2, 4-pentanedione 98\% (TFA), and 1,1,1,5,5,5-Hexaf-luoro-2,4-pentanedione (HFAc) by SigmaAldrich (Darmstadt, Germany). The tri-n-octylphosphine (TOPO), Lanthanum nitrate hexahydrate $\left(\mathrm{La}\left(\mathrm{NO}_{3}\right)_{3} \cdot 6 \mathrm{H}_{2} \mathrm{O}\right)$ and Cerium nitrate hexahydrate $\left(\mathrm{Ce}\left(\mathrm{NO}_{3}\right)_{3} \cdot 6 \mathrm{H}_{2} \mathrm{O}\right)$ were supplied by Sigma Aldrich ${ }^{\circ}$ (Darmstadt, Germany). Synthetic solution containing $\mathrm{La}(1 \mathrm{~g} / \mathrm{L})$ and $\mathrm{Ce}(1 \mathrm{~g} / \mathrm{L})$ were prepared in deionized water $(18.2 \mathrm{~m} \Omega$ ). The $\mathrm{pH}$ level was determined with a $\mathrm{pH}$ meter (Crison', model $\mathrm{pH} 25$ ) calibrated Check $\mathrm{pH} / \mathrm{ORP}$ meter, electrode of the $52 \mathrm{XX}$ series, with buffer solutions of $\mathrm{pH} 4.0,7.0$ and 10.0 with a precision of $10^{-2}$ calibrated.

All samples in the aqueous phase were quantifies by Plasma-Atomic Emission Spectrometer (Agilent Technologies ${ }^{\oplus}$, model 4210 MP-AES) (see Table 1).

\section{Synergistic Extraction Procedure}

The organic phase was prepared by dissolving a $\beta$-diketone (TFA or HFAc) with $0.05 \mathrm{M}$ TOPO in $[\mathrm{Bmim}]\left[\mathrm{Tf}_{2} \mathrm{~N}\right]$ or Kerosene. The initial concentration of TFA 
Table 1. Name and structural formula of compounds used in this work.

\begin{tabular}{|c|c|c|}
\hline Compound & Abbreviation & Structure \\
\hline \multirow[t]{2}{*}{$\begin{array}{l}\text { 1-butyl-3-methylimidazolium } \\
\text { bis(trifluoromethylsulfonyl)imide }\end{array}$} & {$[\mathrm{Bmim}]\left[\mathrm{Tf}_{2} \mathrm{~N}\right]$} & $\mathrm{F}_{3} \mathrm{C}_{\mathrm{O}} \mathrm{O}_{\mathrm{O}}^{\mathrm{S}^{\prime}} \mathrm{N}_{\mathrm{O}}^{-} \mathrm{S}_{\mathrm{O}}^{=} \mathrm{O}$ \\
\hline & & Cation \\
\hline 1,1,1-Trifluoro-2,4-pentanedione & TFA & \\
\hline 1,1,1,5,5,5-Hexafluoro-2,4-pentanedione & HFAc & \\
\hline Tri-n-octylphosphine & TOPO & 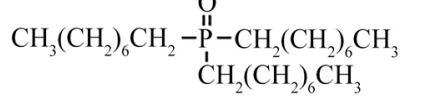 \\
\hline
\end{tabular}

and HFAc in $[\mathrm{Bmim}]\left[\mathrm{Tf}_{2} \mathrm{~N}\right]$ were ranged from $0.05 \mathrm{M}$ to $0.4 \mathrm{M}$ in order to find the minimal concentration quantity of extractant for a feasible extraction. The aqueous solution was prepared by dissolving the $\mathrm{La}(\mathrm{III})$ and $\mathrm{Ce}(\mathrm{III})$ of nitrate hexahydrate in deionized water. The final concentration of the aqueous phase was $1 \mathrm{~g} / \mathrm{L}$ of $\mathrm{La}(\mathrm{III})$ and $1 \mathrm{~g} / \mathrm{L}$ of $\mathrm{Ce}(\mathrm{III})$. The initial $\mathrm{pH}$ of this solution was studied at $\mathrm{pH} 5$.

The $\mathrm{pH}$ of these solutions was measured before and after extraction using a $\mathrm{pH}$ meter. Previous studies have revealed that a high acidity in the aqueous solution results in an obvious decrease in the extraction efficiency of Lns(III) [9] [17]

The removal extraction of $\mathrm{La}(\mathrm{III})$ and $\mathrm{Ce}(\mathrm{III})$ from the aqueous solutions was carried out by means of the same procedure reported in our previous work [18] [19]. The solvent extraction experiments were conducted by contacting $1 \mathrm{~mL}$ of aqueous solution with $1 \mathrm{~mL}$ of organic phase, where the phases were mixed in magnetic stirrers (SBS model ANS-001) at $140 \mathrm{rpm}$ for 40 minutes at room temperature. Then, the phase separation was achieved by centrifugation (Eppendorf Centrifuge model 5418R) at $1000 \mathrm{rpm}$ for 40 minutes. Once these phases were completely separated the concentration of metals in the aqueous phase, before and after distribution, was measure spectrophotometrically (MP-AES) and metal contents in the organic phase were determined by mass balance. All the experiments were realized with duplicate samples.

The percentage of extraction $(\% E)$ was calculated dividing amount of extracted in the organic phase $\left(\left[\mathrm{Ln}^{3+}\right]_{0}\right)$ by its initial amount of metal in the aqueous solution $\left(\left[\mathrm{Ln}^{3+}\right]_{\text {aqi }}\right)$, which is defined by Equation (1):

$$
\% E=\frac{\left[\operatorname{Ln}^{3+}\right]_{\mathrm{o}}}{\left[\mathrm{Ln}^{3+}\right]_{\mathrm{aqi}}} \times 100
$$

The distribution ratio $\left(D_{\mathrm{Ln}^{3+}}\right)$ for the extraction of $\mathrm{Ln}^{3+}$ of two lanthanide ions, $\operatorname{Ln}_{1}$ and $\mathrm{Ln}_{2}$, are defined in the following Equation (2): 


$$
D_{\mathrm{Ln}^{3+}}=\frac{\left[\operatorname{Ln}_{\mathrm{i}}^{3+}-\operatorname{Ln}_{\mathrm{f}}^{3+}\right]}{\left[\operatorname{Ln}_{\mathrm{f}}^{3+}\right]}
$$

where $\operatorname{Ln}_{\mathrm{i}}^{3+}$ and $\operatorname{Ln}_{\mathrm{f}}^{3+}$ represent the initial and final concentrations of $\mathrm{Ln}^{3+}$ in the aqueous phase. The values $\mathrm{f} D_{\mathrm{Ln}^{3+}}$ were measure in duplicated.

The separation factor (SF) was calculated from the value of distribution coefficients of $\mathrm{Ce}(\mathrm{III})$ and $\mathrm{La}(\mathrm{III})$ and shown as Equation (3).

$$
\mathrm{SF}=\frac{D_{\mathrm{Ce}}}{D_{\mathrm{La}}}
$$

From the results previously reported in literature [10], it has been verified that the extraction of $\operatorname{Ln}(\mathrm{III})$ from an aqueous phase using 2-thenoyltrifluoroacetone (HTTA) and TOPO in the IL is governed by the following extraction reaction Equation (4).

$$
\begin{aligned}
& \mathrm{Ln}_{(\text {aq) }}^{3+}+2 \mathrm{Htta}_{(\mathrm{IL})}+3 \mathrm{TOPO}_{(\mathrm{IL})}+\mathrm{C}_{4} \mathrm{mim}^{+} \mathrm{Tf}_{2} \mathrm{~N}_{(\mathrm{IL})}^{-} \\
& \leftrightarrow \mathrm{Ln}(\mathrm{tta})_{2}(\mathrm{TOPO})_{3} \mathrm{Tf}_{2} \mathrm{~N}_{(\mathrm{IL})}+\mathrm{C}_{4} \mathrm{mim}_{(\text {aq) }}^{+}+2 \mathrm{H}_{(\text {(aq })}^{+}
\end{aligned}
$$

On the other hand, the synergistic extraction equilibrium with HTTA and a co-extractant $\mathrm{S}$ in organic solvents is reported [20] to be represented by Equation (5). Where, (aq) and (o) denote the aqueous and organic phases, respectively.

$$
\mathrm{Ln}_{(\text {aq })}^{3+}+3 \mathrm{HTTA}_{\mathrm{o}}+\mathrm{nS}_{(\mathrm{o})} \leftrightarrow \mathrm{M}(\mathrm{TTA})_{3} \mathrm{~S}_{\mathrm{n}(\mathrm{o})}+3 \mathrm{H}_{(\mathrm{aq})}^{+}
$$

\section{Results and Discussion}

The choice of extractants and solvents is vital for the success in the extraction and selectivity of lanthanides. This choice can be made based on synergistic extraction studies. There is available literature on extractants and their application on lanthanide recovery [4] [20] [21] [22] [23].

Extractants, such as $\beta$-diketone and TOPO have been used in synergistic extraction studies of lanthanides [9] [10] [11] [15].

In the present investigation, these extractants were tried with $0.05 \mathrm{M} \beta$-diketone with and without $0.05 \mathrm{M}$ TOPO. The efficiency of the extraction system was measured in terms of percentage extraction (\%E), and separation factor (SF). Table 2 shows the experimental results obtained when extractions of lanthanum and cerium complexes were made using $\beta$-diketone (HFAc and TFA) without TOPO. In the extraction with the absence of TOPO, the amount of water molecules still present in the first coordination sphere of the metal-organic complex decreases the extraction percentages, both in the IL and in kerosene. When using $\beta$-diketone-TOPO (Table 3), the extraction percentage has a remarkable synergistic effect, since TOPO displaces water molecules and generates a more hydrophobic complex it has a greater affinity with the organic phase.

In the results obtained, in Table 2 and Table 3, it is observed that the \%E of $\mathrm{Ce}(\mathrm{III})$ is higher than the $\% \mathrm{E}$ of $\mathrm{La}(\mathrm{III})$ in the HFAc-TOPO system, in both IL 
Table 2. Percentage extraction of $\mathrm{La}$ and Ce for solvent extraction (phase ratio $=1, \mathrm{~T}=298 \mathrm{a}$, agitation $\mathrm{speed}=40 \mathrm{~min}$ ).

\begin{tabular}{ccccc}
\hline \multirow{2}{*}{ Metal ion } & \multicolumn{2}{c}{0.05 M HFAc } & \multicolumn{2}{c}{0.05 M TFA } \\
\cline { 2 - 5 } & Kerosene & {$[$ Kmim] [TF2N] } & $10.67 \pm 1.99$ & $9.01 \pm 2.01$ \\
\hline \%a(III) & $7.82 \pm 3.26$ & $3.68 \pm 0.47$ & $15.83 \pm 1.11$ & $16.46 \pm 0.41$ \\
\hline $\mathrm{Ce}(\mathrm{III})$ & $10.06 \pm 4.39$ & $12.22 \pm 1.80$ & & \\
\hline
\end{tabular}

Table 3. Percentage extraction of $\mathrm{La}$ and Ce for solvent extraction and Separation Factor between Ce/La (phase ratio $=1, \mathrm{~T}=298$ ${ }^{\mathrm{a}} \mathrm{K}$, agitation speed $\left.=40 \mathrm{~min}\right)$.

\begin{tabular}{|c|c|c|c|c|c|c|c|c|}
\hline \multirow{2}{*}{ Metal ion } & \multicolumn{4}{|c|}{$0.05 \mathrm{M}$ HFAc $+0.05 \mathrm{M}$ TOPO } & \multicolumn{4}{|c|}{$0.05 \mathrm{M}$ TFA $+0.05 \mathrm{M}$ TOPO } \\
\hline & Kerosene & SF & {$[\mathrm{Bmim}][\mathrm{TF} 2 \mathrm{~N}]$} & SF & Kerosene & SF & {$[\mathrm{Bmim}][\mathrm{TF} 2 \mathrm{~N}]$} & SF \\
\hline \%La(III) & $70.02 \pm 1.17$ & \multirow[b]{2}{*}{$1.45 \pm 0.01$} & $63.39 \pm 1.26$ & \multirow[b]{2}{*}{$4.96 \pm 0.05$} & $14.49 \pm 1.76$ & \multirow[b]{2}{*}{$3.54 \pm 0.42$} & $33.40 \pm 0.19$ & \multirow[b]{2}{*}{$4.23 \pm 0.12$} \\
\hline$\% \mathrm{Ce}(\mathrm{III})$ & $76.36 \pm 0.85$ & & $89.57 \pm 0.59$ & & $37.55 \pm 0.58$ & & $67.96 \pm 0.43$ & \\
\hline
\end{tabular}

and Kerosene. The same extraction trend is observed in the TFA-TOPO system in IL and Kerosene. This behavior can be explained by the ionic radius of Ce $(0.103 \mathrm{~nm})$ which is smaller than the $\mathrm{La}(0.106 \mathrm{~nm})$. Since the electrostatic interaction between the cation and the ligand should be proportional to the reciprocal of the cationic radius, the stabilities of ionic complexes would be expected to increase through the trivalent lanthanum to lutecium series which may result in an increase in the extraction percentage with a decreasing ionic radius. Such an increase is often observed only in the lighter lanthanides [10] [24]. So, the extraction percentages obtained in our experiments, from both $\mathrm{La}(\mathrm{III})$ and $\mathrm{Ce}(\mathrm{III})$ complexes, are correct. An important aspect of the $\mathrm{La}(\mathrm{III})$ and $\mathrm{Ce}(\mathrm{III})$ extraction with Ionic Liquids is the considerably higher atomic and ionic radii compared to the rare earths, and significantly different chemical properties. The Lns(III) are related through the lanthanide contraction. This property of similar size includes yttrium, which bear a close chemical resemblance, are often grouped together as the Lns(III) [25]. However, its high size makes them very difficult to extract from the liquid solution by forming a complex with the extractant, compared to the rest of the Lns(III).

The choice of $\beta$-diketone type extractants is because they have more affinity with ionic liquids, which prevents them from dissolving in the aqueous phase, decreasing the number of anions available in the $\beta$-diketone for extraction [19].

Furthermore, we want to know how the extraction percentage and the separation factor of the $\beta$-diketonates complexes changes by replacing the methyl group $\left(-\mathrm{CH}_{3}\right)$ of TFA with the fluorinated group $\left(-\mathrm{CF}_{3}\right)$ of HFAc. The results in Table 3, show that the highest $\% E$ of La and Ce are achieved in the HFAc-TOPO systems, due to the difference in acidity that the $\beta$-diketones possess. The tendency to form hydrated complexes is strong for fluorinated ligands, given the great Lewis acidity that these ligands present [6].

The study of hydrophobic ILs has been studied as new solvents for replacing 
VOCs in the extraction processes. ILs can act as ion exchangers (Equation (4)) in solvent extraction. The separability of metal ions in the IL extraction system differs from systems with organic solvents (Equation (5)).

When comparing the $\mathrm{La}(\mathrm{III})$ and $\mathrm{Ce}(\mathrm{III})$ complexes extraction system using TFA-TOPO to IL and Kerosene (Table 3), the results allow us to conclude the following; when using IL as a solvent the best $\% \mathrm{E}$ of $\mathrm{La}(\mathrm{III})$ and $\mathrm{Ce}(\mathrm{III})$ complexes are obtained. This trend has been experimentally demonstrated in the extraction of molybdenum(IV), showing that the use of more hydrophobic IL increases the extractions [26]. In the HFAc-TOPO system, Table 3 shows a high \%E of $\mathrm{La}(\mathrm{III})$ and $\mathrm{Ce}(\mathrm{III})$, in IL and kerosene as solvents, yielding a slight difference in the $\% \mathrm{E}$ of $\mathrm{La}(\mathrm{III})$ and $\mathrm{Ce}(\mathrm{III})$ complexes, between the IL and kerosene.

Regarding the SF, in the HFAc-TOPO system, when Kerosene was used, a SF of $1.45 \pm 0.01$ was achieved. When IL was used, a SF of $4.96 \pm 0.05$ was obtained. In contrast, with the TFA-TOPO system, when Kerosene was used, a SF of 3.54 \pm 0.42 was attained. When IL was used, a SF of $4.23 \pm 0.12$ was obtained. These figures confirm what previous studies have stated; that using IL increases the selectivity of lanthanides [27]. It is worth mentioning that the solvents used in the mining industry, such as Kerosene, have a low polarity and have no place in the chemical reaction. Therefore, they do not participate in the metal extraction process [1] [3] [28], unlike ionic liquids that have been extensively proven to participate in metal extraction by anion exchange [9] [10]. Thus, the choice of solvent is very important not only for synergistic enhancement but also for the effective separation of metals.

Values vary between $0.05 \mathrm{M}$ to $0.4 \mathrm{M}$ of $\beta$-diketones and $0.05 \mathrm{M}$ TOPO were chosen to carry out the further optimization experiments. Larger concentrations of $\beta$-diketones and TOPO could do not be obtained because it was not possible to solubilize them in the mix.

\section{Solvent Extraction of La(III) and Ce(III) Complexes}

The synergistic extraction of $\mathrm{La}(\mathrm{III})$ and $\mathrm{Ce}(\mathrm{III})$ complexes using $\beta$-diketone (TFA or HFAc) and $0.05 \mathrm{M}$ TOPO in the organic phase was researched.

Figure 1 shows the percentage extraction of (\%E) $\mathrm{La}(\mathrm{III})$ and $\mathrm{Ce}(\mathrm{III})$ complexes in $[\mathrm{Bmim}][\mathrm{TF} 2 \mathrm{~N}]$ resulting from an aqueous solution. Figure 1(a) shows a mixture of TFA with $0.05 \mathrm{M}$ TOPO and Figure 1(b) a combination of HFAc with $0.05 \mathrm{M}$ TOPO. As shown in Figure 1, the percentage of extraction of the $\mathrm{Ce}(\mathrm{III})$ complex was relatively higher than the $\mathrm{La}(\mathrm{III})$ complex.

The maximum extraction percentage for the TFA-TOPO system was $42.13 \%$ and $77.48 \%$ for the $\mathrm{La}$ and Ce complexes when $0.4 \mathrm{M}$ TFA and 0.05 M TOPO were used.

The maximum percentage extraction for the HFAc-TOPO system was $94.33 \%$ and $97.67 \%$ for La and Ce complexes when 0.2 M HFAc and 0.05 M TOPO were used.

Regarding the SF (Ce/La) in the TFA-TOPO system (Figure 1(a)), the highest 
SF was $4.91 \pm 0.12$, with $0.4 \mathrm{M}$ TFA and $0.05 \mathrm{M}$ TOPO. In the HFAc-TOPO system (Figure $1(\mathrm{~b})$ ), the topmost SF was $4.96 \pm 0.05$ with $0.05 \mathrm{M}$ HFAc and 0.05 M TOPO. The HFAc-TOPO system tends to be is highly extractive but not selective. The tendency to form hydrated complexes with fluorinated ligands, given the high Lewis acidity that these ligands present [6].

Figure 2 shows the $\% \mathrm{E}$ of $\mathrm{La}(\mathrm{III})$ and $\mathrm{Ce}(\mathrm{III})$ complexes in Kerosene resulting from an aqueous solution. Figure 2(a) displays a mixture of TFA with 0.05 M TOPO and Figure 2(b), a combination of HFAc with $0.05 \mathrm{M}$ TOPO. As shown in Figure 2(a), the \%E of Ce complex was higher than La(III) complex. Figure 2(b), the \%E of $\mathrm{La}$ and Ce complexes were more elevated than $90 \%$ in all cases.

The maximum \%E for the TFA-TOPO system was $27.57 \%$ and $63.70 \%$ for the $\mathrm{La}(\mathrm{III})$ and $\mathrm{Ce}$ (III) complexes when $0.3 \mathrm{M}$ TFA and $0.05 \mathrm{M}$ TOPO were used.

The maximum \%E for the HFAc-TOPO system was $99.87 \%$ and $99.73 \%$ for $\mathrm{La}(\mathrm{III})$ and $\mathrm{Ce}(\mathrm{III})$ complexes when $0.3 \mathrm{M}$ HFAc and 0.05 M TOPO were used.

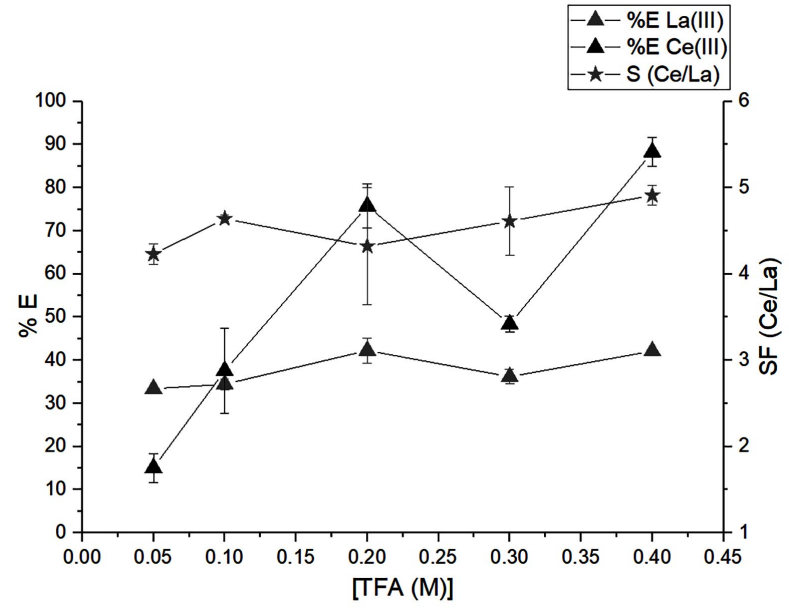

(a) Variation TFA

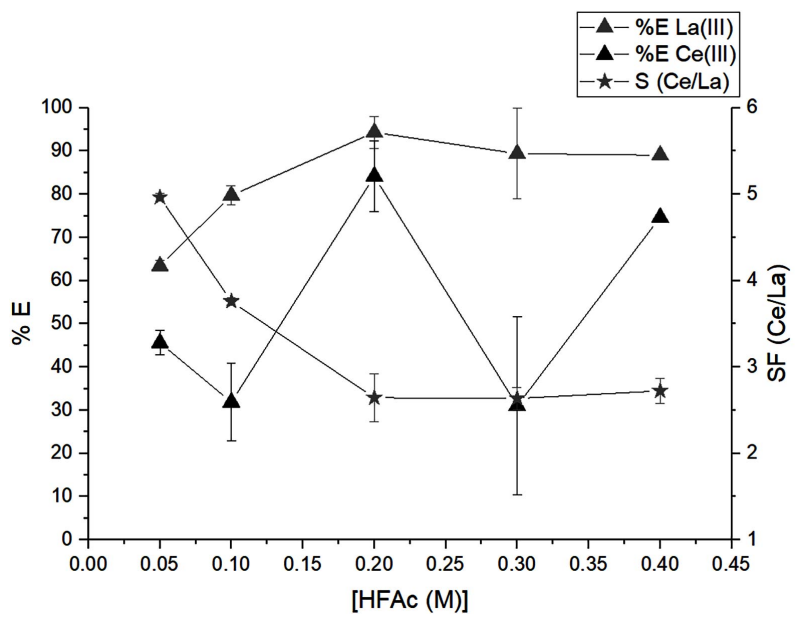

(b) Variation HFAc

Figure 1. Variation of $\beta$-diketone concentration versus percentage extraction $(\% E)$ with $0.05 \mathrm{M}$ TOPO in $[\mathrm{Bmim}]\left[\mathrm{TF}_{2} \mathrm{~N}\right]$. 


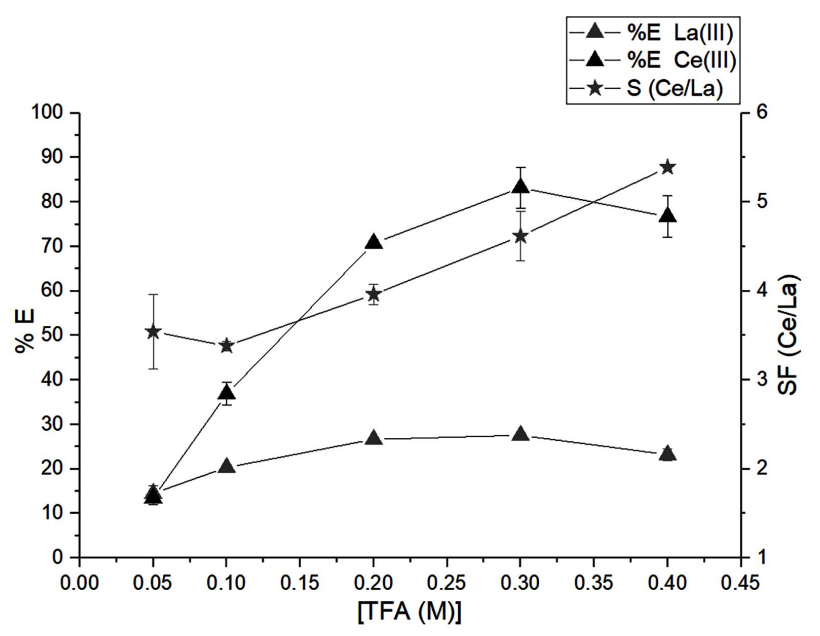

(a) Variation TFA

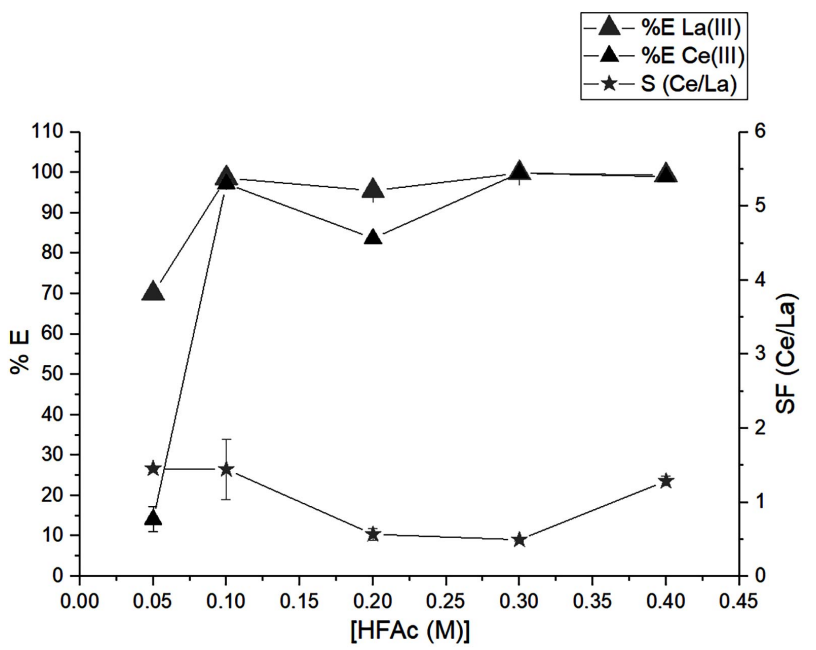

(b) Variation HFAc

Figure 2. Variation of $\beta$-diketone concentration versus percentage extraction $(\% E)$ with $0.05 \mathrm{M}$ TOPO in Kerosene.

Regarding the SF (Ce/La) in the TFA-TOPO system (Figure 2(a)), the highest SF was $5.39 \pm 0.01$, with $0.4 \mathrm{M}$ TFA and $0.05 \mathrm{M}$ TOPO. In the HFAc-TOPO system (Figure 2(b)), the upmost SF was $1.45 \pm 0.05$ with $0.01 \mathrm{M} \mathrm{HFAc}$ and $0.05 \mathrm{M}$ TOPO.

The results of Figure 1 and Figure 2 allowed us to obtain the optimal molar concentration of $\beta$-diketone to achieve maximum SF for TFA-TOPO, HFAcTOPO systems in IL, and Kerosene.

Effect of organic/aqueous (O/A) phase ratio on the Separation Factor of $\mathrm{La}(\mathrm{III})$ and $\mathrm{Ce}(\mathrm{III})$ complexes

Once the best or most economical concentration of extractant was found to improve the synergistic extraction, the effect of organic/aqueous $(\mathrm{O} / \mathrm{A})$ phase ratio was modified in order to assess its effect on the synergistic extraction performance. In the TFA-TOPO system $0.4 \mathrm{M}$ TFA and $0.05 \mathrm{M}$ TOPO were used in the organic phase. In the HFAc-TOPO system 0.05 M HFAc and 0.05 M TOPO 
were used in the organic phase. The effect of $\mathrm{O} / \mathrm{A}$ phase ratio was of 0.2 to 2.0 with a contact time of $40 \mathrm{~min}$.

These concentrations were optimal to achieve the best $\mathrm{Ce} / \mathrm{La} \mathrm{SF}$ in the variation of $\beta$-diketone concentration versus the percentage extraction with $0.05 \mathrm{M}$ TOPO in IL and Kerosene (Figure 1 and Figure 2). Figure 3 shows the results of the effect of O/A phase ratio on the TFA-TOPO (a) and HFAc-TOPO (b) systems in $[\mathrm{Bmim}]\left[\mathrm{TF}_{2} \mathrm{~N}\right]$. Figure $3(\mathrm{a})$ shows that the maximum extraction percentage for the TFA-TOPO system was $82.06 \% \pm 0.02 \%$ and $94.91 \% \pm 0.06 \%$ for the $\mathrm{La}(\mathrm{III})$ and $\mathrm{Ce}(\mathrm{III})$ complexes when the $\mathrm{O} / \mathrm{A}$ phase ratio was 2 . A variation of the O/A phase ratio from 0.2 to 1 increases the SF of Ce/La from 3.97 to 4.97. However, when the O/A phase ratio increases from 1.5 to 2 , the $\mathrm{SF}$ of $\mathrm{Ce} / \mathrm{La}$ decreases from 4.63 to 4.08 . Figure 3 (b) shows that the maximum extraction percentage for the HFAc-TOPO system was $91.51 \% \pm 0.14 \%$ and $97.59 \% \pm 0.03 \%$ for the $\mathrm{La}(\mathrm{III})$ and $\mathrm{Ce}(\mathrm{III})$ complexes. The SF was of $3.75 \pm 0.02$ when the $\mathrm{O} / \mathrm{A}$ phase ratio was 2. Furthermore, a variation of the O/A phase ratio from 0.2 to 1 the SF of Ce/La increases from 1.09 to 4.96. However, when the O/A phase ratio increases from 1.5 to 2 , the $\mathrm{SF}$ of $\mathrm{Ce} / \mathrm{La}$ decreases to $3.75 \pm 0.02$.

Figure 4 shows the effect of O/A phase ratio on the TFA-TOPO (a) and HFAc-TOPO (b) systems in Kerosene. Figure 4(a) shows that the maximum extraction percentage for the TFA-TOPO system was $42.02 \% \pm 0.58 \%$ and $79.21 \% \pm 0.57 \%$ for the $\mathrm{La}(\mathrm{III})$ and $\mathrm{Ce}(\mathrm{III})$ complexes when the $\mathrm{O} / \mathrm{A}$ phase ratio was 2. A variation of the O/A phase ratio from 0.2 to 1.5 increases the SF of $\mathrm{Ce} / \mathrm{La}$ from 3.69 to 5.47. However, when the O/A phase ratio increases to 2, the $\mathrm{SF}$ of $\mathrm{Ce} / \mathrm{La}$ decreases to 5.26. Figure 4(b) shows that the maximum extraction percentage for the HFAc-TOPO system was $96.83 \% \pm 0.03 \%$ and $97.26 \% \pm 0.02 \%$ for the $\mathrm{La}(\mathrm{III})$ and $\mathrm{Ce}(\mathrm{III})$ complexes when the SF was of $1.16 \pm 0.01$ with the $\mathrm{O} / \mathrm{A}$ phase ratio of 2. Furthermore, a variation of the $\mathrm{O} / \mathrm{A}$ phase ratio from 0.2 to 1 the $\mathrm{SF}$ of $\mathrm{Ce} / \mathrm{La}$ increases from $1.12 \pm 0.06$ to $1.45 \pm 0.01$.Nevertherless, when the $\mathrm{O} / \mathrm{A}$ phase ratio increases from 1.5 to 2 , the $\mathrm{SF}$ of $\mathrm{Ce} / \mathrm{La}$ decreases from 1.32 \pm 0.01 to $1.16 \pm 0.01$.

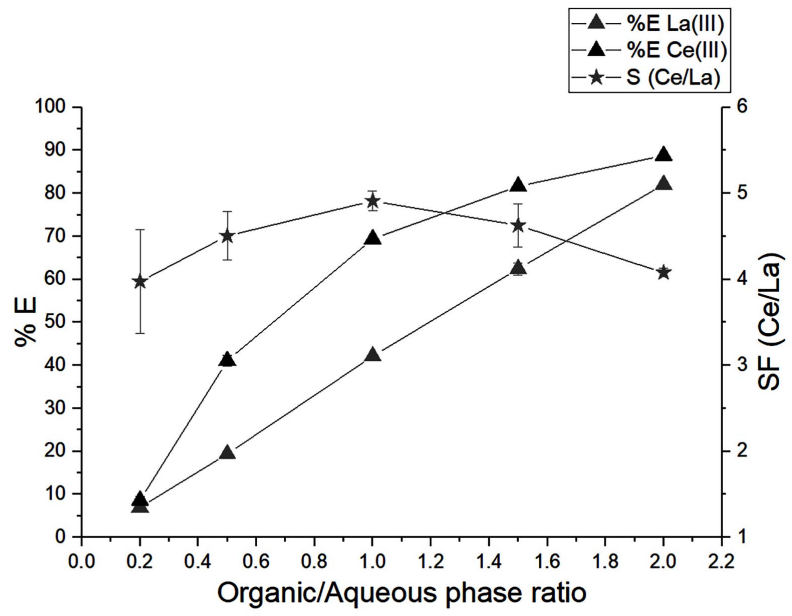

(a) Effect of phase ratio on $\mathrm{Ce}(\mathrm{III})$ and $\mathrm{La}(\mathrm{III})$ complexes with $0.4 \mathrm{M}$ TFA. 


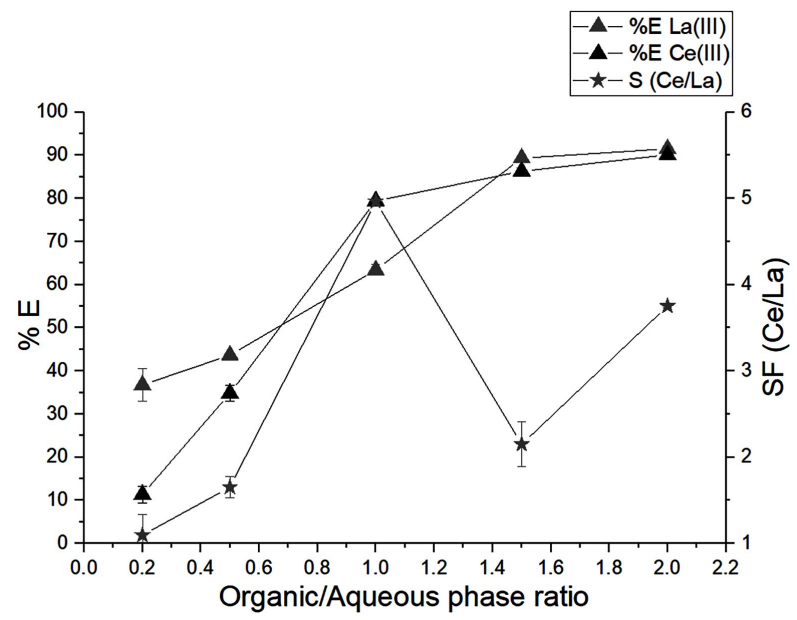

(b) Effect of phase ratio on $\mathrm{Ce}(\mathrm{III})$ and $\mathrm{La}(\mathrm{III})$ complexes with $0.05 \mathrm{M}$ HFAc.

Figure 3. Effect of $\mathrm{O} / \mathrm{A}$ phase ratio on $\mathrm{Ce}(\mathrm{III})$ and $\mathrm{La}(\mathrm{III})$ complexes using $\beta$-diketone and $0.05 \mathrm{M}$ TOPO in $[\mathrm{Bmim}]\left[\mathrm{TF}_{2} \mathrm{~N}\right]$.

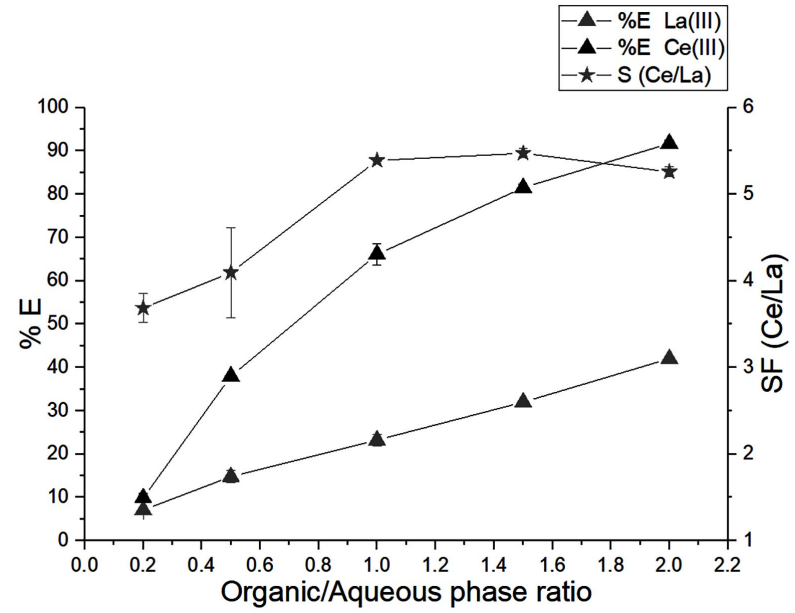

(a) Effect of phase ratio on $\mathrm{Ce}(\mathrm{III})$ and $\mathrm{La}(\mathrm{III})$ complexes with $0.4 \mathrm{M}$ TFA.

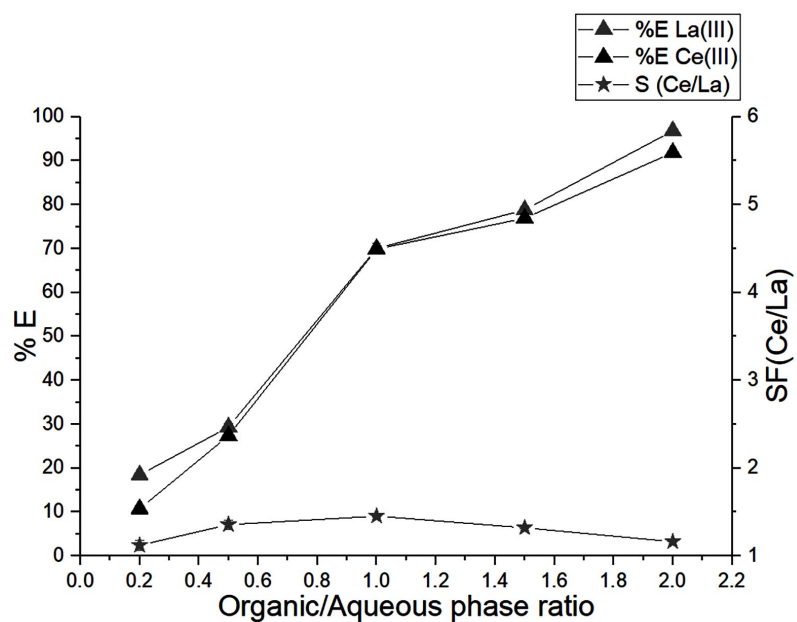

(b) Effect of phase ratio on $\mathrm{Ce}(\mathrm{III})$ and $\mathrm{La}(\mathrm{III})$ complexes with $0.05 \mathrm{M}$ HFAc.

Figure 4. Effect of phase ratio of Ce and La complex using $\beta$-diketone and 0.05 M TOPO in Kerosene. 
Synergistic extraction operating with a volumetric O/A ratio equal to 2 for the TFA-TOPO and HFAc-TOPO system, showed the best extraction percentage for the $\mathrm{Ce}(\mathrm{III})$ and $\mathrm{La}$ (III) complexes in IL. However, when the volumetric O/A ratio was equal to 1 , it achieved the best SF for the TFA-TOPO system. For the HFAc-TOPO system, the best SF was 0.2.

Some studies on the extraction of Cerium(III) and Lanthanum(III) have been performed with HDEHP in kerosene from a hydrochloric acid medium showing a SF of 0.46. Moreover, the SF between Ce-La with Aliquat 336 in xylene from a sodium nitrate medium was 0.60 . Besides, the SF between Ce-La with HDEHP in toluene from a medium of sodium nitrate was 2.70 . The SF between Ce-La with Versatic 911 in Shellsol of a nitrate or chloride medium was 3.00. Reaching low SF values shows that the available $\mathrm{Ce}(\mathrm{III})$ and $\mathrm{La}(\mathrm{III})$ separation methods are not very selective [29].

Other investigations have used a mixture of extractants to develop a synergistic extraction for the separation of Lns(III). For example, 2-thenoyltrifluoroacetone (Htta) with TOPO in n-dodecane [10], 2-thenoyltrifluoroacetone (Htta), 2naphthoyltrifluoroacetone, and benzoylacetate were investigated in the presence of TOPO [13]. Okamura et al found that the SF between La and Ce, Pr and Nd, $\mathrm{Sm}$ and $\mathrm{Eu}$, and $\mathrm{Eu}$ and $\mathrm{Gd}$ with $\mathrm{Htta}$ and TOPO in $\left[\mathrm{C}_{4} \mathrm{mim}\right]\left[\mathrm{Tf}_{2} \mathrm{~N}\right]$ is higher than that with D2EHPA or PC-88A in isooctane [9]. Additionally, it was found that the separation of Lns(III) varied with the acidity of the $\beta$-diketones, for example, the SF between $\mathrm{Eu}(\mathrm{III})$ and $\mathrm{Lu}(\mathrm{III})$ in the synergistic system using benzoylacetone (Hba) with a higher $\mathrm{pKa}$ is significantly larger than those with the other $\beta$-diketones [11]. Therefore, the $\beta$-diketones have been used in various synergistic combinations to achieve high Lns(III) SF.

The TFA-TOPO system achieved a better SF in IL when using low concentrations of TFA than in Kerosene. In the HFAc-TOPO system, the best SF was completed when IL was used as the solvent. Ionic liquid confers selectivity by increasing the SF. This allows the search for new ionic liquids and $\beta$-diketones, increasing the SF of adjacent elements such as $\mathrm{La}$ (III) and $\mathrm{Ce}(\mathrm{III})$ complexes.

\section{Conclusions}

This present study investigated the percentage extraction and separation factor of Lanthanum(III) and Cerium(III) complexes using a combination of $\beta$-diketone (TFA or HFAc) with $0.05 \mathrm{M}$ TOPO.

The results indicated that when only $\beta$-diketone was used in a solvent, the percentage of extraction of $\mathrm{La}(\mathrm{III})$ and $\mathrm{Ce}(\mathrm{III})$ was lower than when $\beta$-diketoneTOPO were used together. The addition of TOPO improved extraction efficiency of the $\mathrm{La}(\mathrm{III})$ and $\mathrm{Ce}(\mathrm{III})$ complexes in IL and Kerosene. These results were similar to those found in the bibliography.

The use of $\beta$-diketones with fluorinated groups (HFAc) achieved a high percentage of lanthanide extraction, with only 0.05 M HFAC and 0.05 M TOPO. However, the factor of separation between adjacent lanthanides was low. The 
TFA-TOPO system achieved good extraction percentages and separation factors. The synergistic extraction demonstrated that we could achieve an excellent removal of $\mathrm{La}(\mathrm{III})$ and $\mathrm{Ce}(\mathrm{III})$ complexes with IL and Kerosene. Tests using IL showed that the TFA-TOPO system made the best a percentage extraction compared to the use of Kerosene. Also, IL achieved a lower SF than Kerosene.

On the other hand, the HFAc-TOPO system in IL and Kerosene achieved good levels of extraction. Nevertheless, the best SF was obtained using IL as a solvent. It is necessary to continue designing cations and anions to form hydrophobic ionic liquids that confer higher separation factors.

Regarding the O/A ratio effect, the best ratio was 1, obtaining a SF of 4.91 for TFA-TOPO in IL. For HFAc-TOPO, the best result was 1, acquiring a SF of 4.96 in IL. For TFA-TOPO the best result was 1, obtained with a SF of 5.39 in Kerosene, and for HFAc-TOPO the best result was 1, gotten with a SF of 1.45 in Kerosene.

In future works, the extraction percentage and the separation factor could be studied with a lower HFAc concentration than that researched in the present study. Also, an alternative to TOPO could be sought, in order to obtain better separation factors.

The knowledge obtained in this study can lead to further progress in the development of Lns(III) distribution systems in IL and in Kerosene.

\section{Acknowledgements}

This study has been supported by the Laboratory of Membrane Separation Processes, LabProSeM and ANID PFCHA/DOCTORADO NACIONAL BECAS CHILE/2016-21160816 (A.Q.).

\section{Conflicts of Interest}

The authors declare no conflicts of interest regarding the publication of this paper.

\section{References}

[1] Kumari, A., Panda, R., Jha, M.K., Kumar, J.R. and Lee, J.Y. (2015) Process Development to Recover Rare Earth Metals from Monazite Mineral: A Review. Minerals Engineering, 79, 102-115. https://doi.org/10.1016/j.mineng.2015.05.003

[2] Hasegawa, Y., Tamaki, S., Yajima, H., Hashimoto, B. and Yaita, T. (2011) Selective Separation of Samarium(III) by Synergistic Extraction with $\beta$-Diketone and $\mathrm{Me}$ thylphenylphenanthroline Carboxamide. Talanta, 85, 1543-1548. https://doi.org/10.1016/j.talanta.2011.06.041

[3] Jha, M.K., Kumari, A., Panda, R., Kumar, J.R., Yoo, K. and Lee, J.Y. (2016) Review on Hydrometallurgical Recovery of Rare Earth Metals. Hydrometallurgy, 165, 2-26. https://doi.org/10.1016/j.hydromet.2016.01.035

[4] Tian, M., Jia, Q. and Liao, W. (2013) Studies on Synergistic Solvent Extraction of Rare Earth Elements from Nitrate Medium by Mixtures of 8-Hydroxyquinoline with Cyanex 301 or Cyanex 302. Journal of Rare Earths, 31, 604-608. https://doi.org/10.1016/S1002-0721(12)60328-7 
[5] Xie, F., Zhang, T.A., Dreisinger, D. and Doyle, F. (2014) A Critical Review on Solvent Extraction of Rare Earths from Aqueous Solutions. Minerals Engineering, 56, 10-28. https://doi.org/10.1016/j.mineng.2013.10.021

[6] Binnemans, K. (2005) Rare-Earth Beta-Diketonates. In: Vitalij, P. and Bunzli, J.-C., Eds., Handbook on the Physics and Chemistry of Rare Earths, Elsevier, Amsterdam, 107-272. https://doi.org/10.1016/S0168-1273(05)35003-3

[7] Umetani, S. (2006) Molecular Design of Organic Ligands Highly Selective for Lanthanide Metal Ions. Journal of Alloys and Compounds, 408-412, 981-984.

https://doi.org/10.1016/j.jallcom.2004.12.089

[8] Umetani, S., Kawase, Y., Le, Q.T.H. and Matsui, M. (2000) Acylpyrazolone Derivatives of High Selectivity for Lanthanide Metal Ions: Effect of the Distance between the Two Donating Oxygens. Journal of the Chemical Society, Dalton Transactions, 15, 2787-2791.

[9] Okamura, H., Mizuno, M., Hirayama, N., Shimojo, K., Naganawa, H. and Imura, H. (2019) Synergistic Enhancement of the Extraction and Separation Efficiencies of Lanthanoid(III) Ions by the Formation of Charged Adducts in an Ionic Liquid. Industrial \& Engineering Chemistry Research, 59, 329-340. https://doi.org/10.1021/acs.iecr.9b04998

[10] Zhao, Z., et al. (2014) Synergistic Extraction of Rare-Earth Metals and Separation of Scandium Using 2-Thenoyltrifluoroacetone and Tri-N-Octylphosphine Oxide in an Ionic Liquid System. Journal of Chemical Engineering of Japan, 47, 656-662.

[11] Hatakeyama, M., Nishiyama, Y., Nagatani, H., Okamura, H. and Imura, H. (2018) Synergistic Extraction Equilibrium of Lanthanide(III) Ions with Benzoylacetone and a Neutral Ligand in an Ionic Liquid. Solvent Extraction Research and Development Japan, 25, 79-89.

[12] Atanassova, M., Kurteva, V. and Dukov, I. (2016) The Interaction of Extractants During Synergistic Solvent Extraction of Metals. Is It an Important Reaction?. RSC Advances, 6, 81250-81265. https://doi.org/10.1039/C6RA18478B

[13] Okamura, H., Takagi, H., Isomura, T., Morita, K., Nagatani, H. and Imura, H. (2014) Highly Selective Synergism for the Extraction of Lanthanoid(III) Ions with $\beta$-Diketones and Trioctylphosphine Oxide in an Ionic Liquid. Analytical Sciences, 30, 323-325. https://doi.org/10.2116/analsci.30.323

[14] Kikuchi, Y., Matsumiya, M. and Kawakami, S. (2014) Extraction of Rare Earth Ions from Nd-Fe-B Magnet Wastes with TBP in Tricaprylmethylammonium Nitrate. Solvent Extraction Research and Development, 21, 137-145.

https://doi.org/10.15261/serdj.21.137

[15] Okamura, H., Takagi, H., Isomura, T., Morita, K., Nagatani, H. and Imura, H. (2014) Highly Selective Synergism for the Extraction of Lanthanoid(III) Ions with $\beta$-Diketones and Trioctylphosphine Oxide in an Ionic Liquid. Analytical Sciences, 30, 323-325. https://doi.org/10.2116/analsci.30.323

[16] Rout, A. and Binnemans, K. (2015) Influence of the Ionic Liquid Cation on the Solvent Extraction of Trivalent Rare-Earth Ions by Mixtures of Cyanex 923 and Ionic Liquids. Dalton Transactions, 44, 1379-1387. https://doi.org/10.1039/C4DT02766C

[17] Wang, L., Huang, X., Yu, Y. and Long, Z. (2014) Kinetics of Rare Earth Pre-Loading with 2-Ethylhexyl Phosphoric Acid Mono 2-Ethylhexyl Ester [HEH(EHP)] Using Rare Earth Carbonates. Separation and Purification Technology, 122, 490-494. https://doi.org/10.1016/j.seppur.2013.12.007 
[18] Castillo, J., Teresa, M., Fortuny, A., Navarro, P., Sepúlveda, R. and María, A. (2014) $\mathrm{Cu}(\mathrm{II})$ Extraction Using Quaternary Ammonium and Quaternary Phosphonium Based Ionic Liquid. Hydrometallurgy, 141, 89-96. https://doi.org/10.1016/j.hydromet.2013.11.001

[19] Sepúlveda, R., Castillo, J., Plaza, A., Sánchez, J., Torres, A. and Romero, J. (2017) Improvement of Recovery Performance in the Solvent Extraction of $\mathrm{Cu}$ (II) Using $[$ bmim $]\left[\mathrm{Tf}_{2} \mathrm{~N}\right]$ and a $\beta$-Diketone as Extractant and Its Stripping with Supercritical Carbon Dioxide. J. Supercrit. Fluids, 128, 26-31.

https://doi.org/10.1016/j.supflu.2017.05.003

[20] Khopkar, P.K. and Mathur, J.N. (1977) Synergistic Extraction of Some Trivalent Actinides and Lanthanides by Thenoyltrifluoroacetone and Aliquat Chloride. Journal of Inorganic and Nuclear Chemistry, 39, 2063-2067.

https://doi.org/10.1016/0022-1902(77)80548-4

[21] Modolo, G. and Odoj, R. (1999) Synergistic Selective Extraction of Actinides(III) over Lanthanides from Nitric Acid Using New Aromatic Diorganyldithiophosphinic Acids and Neutral Organophosphorus Compounds. Solvent Extraction and Ion Exchange, 17, 33-53. https://doi.org/10.1080/07360299908934599

[22] Nakamura, S., Surakitbanharn, Y. and Akiba, K. (1990) Synergistic Extraction of Europium and Thulium by Mixtures of High Molecular Weight $\beta$-Diketones and Neutral Organophosphorus Esters. Analytical Sciences, 6, 295-299. https://doi.org/10.2116/analsci.6.295

[23] Rey, J., Atak, S., Dourdain, S., Arrachart, G., Berthon, L. and Pellet-Rostaing, S. (2017) Synergistic Extraction of Rare Earth Elements from Phosphoric Acid Medium Using a Mixture of Surfactant AOT and DEHCNPB. Solvent Extraction and Ion Exchange, 35, 321-331. https://doi.org/10.1080/07366299.2017.1362852

[24] Murthy, K., Krupadam, R. and Anjaneyulu, Y. (1998) Studies on the Solvent Extraction of Trivalent Lanthanides with Hexafluoroacetylacetone (HFAA) and Tri-NOctylphosphineoxide (TOPO). Proceedings of the Indian Academy of Sciences, 110, 83-88.

[25] Cotton, S.A. (2006) Scandium, Yttrium \& the Lanthanides: Inorganic \& Coordination Chemistry. In: King, R.B., eds., Encyclopedia of Inorganic Chemistry, John Wiley \& Sons, Ltd., Hoboken, 1-40.

[26] Quijada-Maldonado, E., Torres, M.J. and Romero, J. (2017) Solvent Extraction of Molybdenum (VI) from Aqueous Solution Using Ionic Liquids as Diluents. Separation and Purification Technology, 177, 200-206. https://doi.org/10.1016/j.seppur.2016.12.045

[27] Akashima, K.N., Ubota, F.K., Aruyama, T.M. and Oto, M.G. (2003) Ionic Liquids as a Novel Solvent for Lanthanide Extraction. Analytical Sciences, 19, 1097-1098.

[28] Thakur, N.V. (2000) Separation of Rare Earths by Solvent Extraction. Mineral Processing and Extractive Metallurgy Review, 21, 277-306. https://doi.org/10.1080/08827500008914171

[29] Gupta, C.K.K. and Krishnamurthy, N. (2005) Extractive Metallurgy of Rare Earths. International Materials Reviews, 37, 197-248. https://doi.org/10.1179/imr.1992.37.1.197 